\title{
CRÓNICA SOBRE EL COLOQUIO «CONCEPTOS MULTIDIMENSIONALES, CLÁUSULAS GENERALES, ESTÁNDARES DE CONDUCTA: ORDEN PÚLICO, BUENA FE, PAUTAS DE CONDUCTA Y DILIGENCIA»
}

Review of the seminar «multidimensional concepts, general clauses, standards of conduct: punish order, good faith, guidelines of behavior and diligence»

DOI: http://dx.doi.org/10.15304/dereito.27.2.5644

Mónica GARCÍA GoldAR

Investigadora del Subprograma Estatal de Formación de Doctores

Universidade de Santiago de Compostela

monica.garcia@usc.es

\section{Resumen}

Este texto tiene por objeto comentar el reciente Coloquio entre filósofos y privatistas que tuvo lugar los días 27 y 28 de noviembre en la facultad de Derecho de la Universidad de Santiago de Compostela.

Palabras clave: Coloquio, Derecho Civil, Filosofía del Derecho.

\section{Abstract}

The aim of this paper is to report the recent Colloquium regarding Civil Law and Philosophy of Law that took place on the $27^{\text {th }}$ and $28^{\text {th }}$ of November at the Faculty of Law, Santiago de Compostela.

Keywords: Colloquium, Civil Law, Philosophy of Law.

Quisiera comenzar esta crónica agradeciendo a quien me propuso hacerla por la estupenda ocasión que me ha brindado para expresar ciertas cosas al hilo de la misma. Sea como fuere, y antes de entrar a valorar el Coloquio en sí, quisiera hacer un breve inciso acerca del sentido y origen del mismo.

Esta reunión se trataba del III Coloquio entre civilistas y filósofos del Derecho. El primer encuentro se produjo en Zaragoza en el año 2014, bajo el título de "La ignorancia de la ley no excusa su cumplimiento". Posteriormente, la segunda edición se realizó en noviembre de 2016 en León, sobre responsabilidad civil y relaciones familiares, en el que tuve el privilegio de participar. Finalmente, la tercera y última edición (por ahora) se llevó a cabo los pasados días 27 y 28 de noviembre en la Facultad de Derecho de la Universidad de Santiago de Compostela. Como quiera que las impresiones de todos los coloquios han sido muy positivas, parece que este foro de debate interdisciplinar seguirá teniendo, por fortuna, continuación en el futuro.

La finalidad de estos encuentros es, en palabras de sus promotores, el Profesor Jesús Delgado Echeverría, de la Universidad de Zaragoza, y el

Recibido: 21/11/2017. Aceptado: 12/03/2018. 
Profesor Manuel Atienza, de la Universidad de Alicante, propiciar un acercamiento y colaboración intelectual entre civilistas y filósofos del Derecho de diferentes Universidades españolas. Finalidad que se ha cumplido sobradamente en este último encuentro a la vista de los interesantes intercambios de opinión que se produjeron entre los juristas que allí se dieron cita (no sólo civilistas y filósofos del Derecho, sino también iusprivatistas y mercantilistas).

Los directores de este tercer encuentro, los Profesores María Paz García Rubio, de la Universidad de Santiago de Compostela, y Josep Joan Moreso, de la Universitat Pompeu Fabra, estructuraron las jornadas en tres grandes bloques: el primero versaba sobre el orden público, en el que hubo dos ponencias generales por parte de Santiago Álvarez González y Manuel Atienza; el segundo trataba sobre la buena fe, cuya ponencia general fue ofrecida por José María Miquel; y el tercero guardaba relación con los criterios o pautas y estándares de conducta, tales como el "buen padre de familia" o la lex artis, entre otros, y en el que participaron Juan Antonio García Amado y Ricardo de Ángel, en este último caso por videoconferencia. Además, durante toda la jornada los allí asistentes pudimos profundizar si cabe un poco más en las cuestiones tratadas gracias a las más de veintitrés intervenciones programadas y distribuidas entre los tres grandes bloques temáticos.

Entre todos los asuntos que se abordaron, se puede destacar el análisis crítico de las nociones propuestas para debate, sobre las que varios de los asistentes sugirieron una revisión. Así, además sobre el concepto y función de las cláusulas generales, y entre otras cuestiones, se propuso sustituir el concepto de orden público por el de principios fundamentales del Derecho, o el del buen padre de familia por uno menos sexista, menos rígido y más adaptable a las circunstancias de cada caso. Además, se debatió largo y tendido acerca de estos conceptos multidimensionales o jurídicamente indefinidos y se plantearon numerosos interrogantes, como el de si hay orden público más allá de los imperativos constitucionales. En definitiva, se analizó el Derecho y los fundamentos más básicos de nuestro sistema jurídico (principios, reglas y normas) desde una perspectiva funcional y multidisciplinar que resultó enriquecedor en todos los sentidos.

Pero si algo debe ser destacado por encima de todo, ello debería ser, en mi opinión, el formato. $Y$ es que este coloquio no se desenvolvió en el formato habitual y tradicional; más bien al contrario, por la disposición del lugar y la mesa redonda, parecía tratarse de una reunión entre expertos, más que de un seminario propiamente dicho. Tal vez por ello, o tal vez por la confianza que se notaba entre viejos amigos o conocidos, el debate fue intenso y fluido, y ciertamente ilustrativo para todos los que tuvimos la suerte de asistir a este encuentro. Particularmente en mi caso, pues a punto de finalizar la travesía de aprendizaje incesante que supone el doctorado, no se me ocurre, sinceramente, mejor broche final. Sabido es por todos que la carrera académica es incierta y a menudo precaria. Que es mucho lo que aporta, pero también mucho a lo que se renuncia. Pero 
es por seminarios como este, en el que se debaten cuestiones jurídicas de forma tan directa, vehemente y entusiasta, que todo vale la pena. 